\title{
STUDI PENGELOLAAN SUMBER DAYA PESISIR DI DESA BATUNUNGGUL KECAMATAN NUSA PENIDA
}

\author{
I Ketut Sudiartawan \\ I Wayan Treman, S.Pd, M.Sc. I Gede Budiarta, S.Pd, M.Si. \\ Program Studi Pendidikan Geografi \\ Fakultas Hukum dan IImu Sosial \\ Universitas Pendidikan Ganesha \\ Singaraja, Bali, Indonesia
}

Email : ketutsudiartawan666@gmail.com

\begin{abstract}
Abstrak
Penelitian ini dilaksanakan di Desa Batununggul Kecamatan Nusa Penida dengan tujuan untuk: (1)Mendeskripsikan karakteristik sumber daya pada wilayah pesisir Desa Batununggul Kecamatan Nusa Penida, dan (2) mendeskripsikan pengelolaan sumber daya pesisir di wilayah pesisir Desa Batununggul. Berkenan dengan itu penelitian dirancang sebagai penelitian deskriptif, dengan sampel jumlah sampel 55 orang $(50 \%)$ dari populasi yang berjumlah 108 orang yang diambil secara proposive sampling. Data dikumpulkan melalui observasi dan kuesioner yang selanjutnya dianalisis menggunakan metode diskrptif kualitatif. Hasil penelitian menunjukan bahwa (1) Karateristik sumber daya pesisir Desa Batununggul sudah menunjukan indikator fisik dan bilogis dari karakteristik sumber daya pesisir daerah Batununggul yang masih dijaga dan di manfaatkan dengan baik tanpa merusak lingkungan fisik maupun biologis dari sumber daya pesisir tersebut, (2) cara pengelolaan sumber daya pesisir Desa Batununggul sudah di kelola dan dijaga dengan baik oleh masyarakat setempat, ini dapat kita lihat dari hasil penangkapan ikan dan hasil dari pembudidayaan rumput laut, dan (3) cara pengelolaan sumber daya hayati, non hayati, dan buatan di Desa Batununggul tergolong sangat baik, ini dapat kita lihat dari hasil analisis data yang menunjukan para nelayan masih menggunakan cara tradisional untuk menangkap ikan dan membudidayakan rumput laut. Selain itu, penggunan pasir juga masih terjaga atau di batasi sehingga tidak menimbulkan abrasi di sekitaran daerah pesisir. Untuk di bidang pembangunan tempat rumah kelompok nelayan juga tidak merusak lingkungan setempat karena tempat rumah tersebut dibuat dan di tata rapi oleh masyarakat.
\end{abstract}

Kata kunci: Karateristik, Pengelolaan, Sumber Daya Pesisir.

\begin{abstract}
This research was conducted in Batununggul Village, Nusa Penida Subdistrict with the objectives to: (1) Describe the characteristics of resources in the coastal area of Batununggul Village, Nusa Penida Subdistrict, and (2) to describe coastal resource management in coastal area of Batununggul Village. The study was designed as a
\end{abstract}


descriptive study, with a sample sample of 55 people $(50 \%)$ of a population of 108 people taken by proposive sampling. Data were collected through observation and questionnaire which then analyzed using qualitative discrptive method. The result of the research shows that (1) Characteristic of coastal resources of Batununggul Village shows the physical and biological indicators of coastal resources characteristic of Batununggul area which is still maintained and utilized well without damaging the physical and biological environment of the coastal resources, (2) The management of coastal resources of Batununggul Village has been managed and well maintained by the local people, we can see from the catching of fish and the result of seaweed cultivation, and (3) the way of biological, non-biological, and artificial resources management in Batununggul Village Classified as very good, we can see from the data analysis that shows the fishermen still use traditional way to catch fish and cultivate seaweed. In addition, the use of sand is also still awake or in the limit so as not to cause abrasion in the surrounding coastal areas. For in the field of construction where the home group of fishermen also do not damage the local environment because the place of the house is made and in the order by the community.

Keywords: Characteristics, Management, Coastal Resources.

\section{PENDAHULUAN}

Indonesia merupakan salah satu negara kepulauan terbesar di dunia, dengan sekitar 17.508 buah pulau yang membentang sepanjang $5.120 \mathrm{~km}$ dari timur ke barat sepanjang khatulistiwa dan $1.760 \mathrm{~km}$ dari utara ke selatan (Supriharyono, 2000). Luas daratan Indonesia mencapai 1.9 juta $\mathrm{km}^{2}$ dan luas perairan tercatat $7,9 \mathrm{~km}^{2}$. Lebih lanjut Negara Indonesia memiliki garis pantai sekitar $81.791 \mathrm{~km}$, yang merupakan salah satu negara di dunia dengan pantai yang panjang. Mengingat perairan pantai atau pesisir merupakan perairan yang sangat produktif, maka panjangnya pantai Indonesia merupakan potensi sumber daya alam yang besar untuk pembangunan ekonomi di negara ini (Supriharyono, 2000).

Sebagai negara kepulauan, laut merupakan wilayah terluas di Indonesia dibandingkan daratan. Sebagian besar masyarakat Indonesia tinggal di sepanjang garis pantai, hal ini menyebabkan masyarakat di daerah pesisir untuk bekerja dan menggantungkan hidupnya pada potensi dari laut, yang sering kita sebut sebagai nelayan.

Bali termasuk salah satu daerah tujuan wisata bagi tamu mancanegara. Ketika Indonesia dilanda krisis moneter Bali tidak surut dalam pengembangan sektor pariwisata. Bali dengan latar kebudayaannya dan aspek lainnya pada mulanya hanya untuk di abadikan demi keagungan masyarakatnya di nikmati oleh masyarakat Bali.

Berdasarkan data monografi Kecamatan Nusa Penida memiliki luas $20.284 \mathrm{~km}^{2}$ yang terdiri dari 16 desa. Kecamatan Nusa Penida tergolong landai sampai berbukit, dimana untuk daerah pesisir sepanjang pantai bagian utara berupa lahan datar dengan kemiringan 0-3\% dari ketinggian lahan 0$268 \mathrm{~m}$ di atas permukaan laut (dpl) dan semakin ke selatan kemiringan lerengnya semakin bergelombang 
(Monografi Kecamatan Nusa Penida Tahun 2015).

Di sekitaran pesisir sepanjang pantai dijumpai beberapa kelompokkelompok nelayan yang tersebar dipinggiran pantai Kecamatan Nusa Penida terutama di Desa Batununggul. Desa Batununggul secara astronomis terletak pada posisi $8^{\circ} 41^{\prime} 50.465^{\prime \prime}$ LS dan $115^{\circ} 34^{\prime} 58.550 \mathrm{BT}$ (Zonasi Kawasan Konservasi Perairan Daerah NusaPenida Kabupaten Klungkung, Bali, Hal.16. 2015) memiliki luas $1.345 \mathrm{Ha}$, dengan batas wilayah sebelah utara laut, sebelah selatan Desa Kutampi, seelah barat Kutampi Kaler, dan sebelah timur Desa Suana. Kondisi Topografinya ialah daerah perbukitan memiliki luas 75 ha, sedangkan daratan memiliki luas 525 (Profil Desa / Kelurahan Batununggul, 2016).

Di Desa Batununggul memiliki sebuah kelompok nelayan tradisional, kelompok nelayan yang ada di Desa Batununggul yakni terdidri dari 4 kelompok setiap kelompok memiliki 90 anggota, setiap harinya mereka bekerja menangkap ikan dan juga menanam tanaman laut (Rumput laut) dengan menggunakan perahu (Jukung) dan peralatan yang masih bersifat tradisional sesuai kondisi atau cuaca air laut. Selain adanya kegiatan nelayan

\section{METODE}

Penelitian ini berlokasi di wilayah pesisir Desa Batunuggul, Kecamatan Nusa Penida. Objek pada penelitian ini adalah pengelolaan sumber daya pesisir di Desa Batununggul, Kecamatan Nusa Penida, sedangkan yang menjadi subjek penelitian ini adalah para nelayan yang ada di dalam kelompok nelayan tradisional. Penelitian ini menggunakan Penelitian ini merupakan penelitian tradisional di Desa Batununggul, di pesisir Desa Batununggul juga dimanfaatkan sebagai pelabuhan boat dan perahu sampan yang menghubungkan antara Nusa Penida dengan pelabuhan Kusambe dan Sanur.

Dilihat dari kegiatan wilayah pesisir Desa Batununggul pasti akan mempengaruhi kondisi sumber daya pada wilayah pesisir yaitu sumber daya hayati, non hayati dan Buatan di Desa Batununggul yang akan menimbulkan dampak positif maupun negatif terhadap wilayah tersebut. Selain itu, kegiatan di wilayah pesisir Desa Batununggul juga mempengaruhi cara pengelolaan sumber daya di wilayah pesisir Desa Batununggul. menganalisis dan menampilkan

Permasalahan pada penelitian ini (1) Bagaimankah Karakteristik Sumber Daya Pada Wilayah Pesisir Desa Batununggul Kecamatan Nusa Penida, (2) Bagaimana pengelolaan Sumber Daya Pesisir di wilayah Pesisir Desa Batununggul.,

Tujuan dari penelitian

Mendeskripsikan karakteristik sumber daya pada wilayah pesisir Desa Batununggul Kecamatan Nusa Penida , (2) Mendeskripsikan pengelolaan sumber daya pesisir di wilayah pesisir Desa Batununggul.

deskriptif. Penelitian Deskritif adalah penelitian yang diarahkan untuk memberikan gejala-gejala, faktafakta atau kejadian secara sistematis dan akurat mengenai sifat-sifat populasi atau daerah tertentu penelitian deskriptif ini berkenaan dengan pendeskripsian tentang suatu fenomena yang di analisis dilakukan dengan cara sistematis dan 
faktual antara suatu variabel dan variabel lainnya (Zuriah,2007: 47).

. Data yang digunakan adalah data primer dan sekunder. Data sekunder bersumber dari Badan Pusat statistik Kabupaten Klungkung. Data primer yang telah dikumpulkan selanjutnya akan dianalisis menggunakan analisis deskriptif kualitatif menggunakan pendekatan keruangan. karateristik sumber daya pesisir di Desa Batununggul Kecamatan Nusa Penida menggunakan analisis deskriptif kualitatif dengan pendekatan kelingkungan. dan pengelolaan sumber daya pesisir di Desa Batununggul Kecamatan Nusa Penida akan menggunakan analisis deskriptif kualitatif dengan pendekatan kelingkungan.

\section{HASIL DAN PEMBAHASAN}

\section{Karakteristik Sumber Daya Pada Wilayah Pesisir Desa Batununggul}

Karekteristik sumber daya pada wilayah pesisir Desa Batununggul meliputi beberapa indikator yaitu fisik dan bilologis.

\section{Pernyataan Responden (Kelompok Nelayan) Terhadap Kondisi Pasir Desa Batununggul}

\begin{tabular}{|c|c|c|c|c|c|c|c|c|c|}
\hline \multirow{3}{*}{$\begin{array}{l}N \\
0\end{array}$} & \multirow{3}{*}{$\begin{array}{c}\text { Nama } \\
\text { kelompok }\end{array}$} & \multicolumn{6}{|c|}{ Kondisi pasir } & \multirow{3}{*}{$\begin{array}{c}\text { Total } \\
\mathbf{N}\end{array}$} & \multirow{3}{*}{$\%$} \\
\hline & & \multicolumn{2}{|c|}{$\mathbf{A}$} & \multicolumn{2}{|c|}{ B } & \multicolumn{2}{|c|}{ C } & & \\
\hline & & $\mathbf{N}$ & $\%$ & $\mathbf{N}$ & $\%$ & $\mathbf{N}$ & $\%$ & & \\
\hline 1 & $\begin{array}{l}\text { Punyan } \\
\text { Togol } \\
\text { Segara }\end{array}$ & 10 & 71,4 & 4 & $\begin{array}{c}28 \\
6\end{array}$ & 0 & 0 & 14 & 100 \\
\hline 2 & Nusa Bahari & 9 & 75 & 3 & $\begin{array}{c}17 \\
6\end{array}$ & 0 & 0 & 12 & 100 \\
\hline 3 & $\begin{array}{l}\text { Astitining } \\
\text { Samudra }\end{array}$ & 6 & 54,5 & 5 & $\begin{array}{c}45 \\
5\end{array}$ & 0 & 0 & 11 & 100 \\
\hline 4 & Sri Bhakti & 15 & 83,3 & 3 & $\begin{array}{c}16 \\
7\end{array}$ & 0 & 0 & 18 & \\
\hline & Rata - rata & - & 70,9 & - & $\begin{array}{c}27, \\
1\end{array}$ & - & 0 & - & - \\
\hline
\end{tabular}

Sumber: Analisis data primer 2017

Keterangan : 
$A=$ Sudah dilakukan penjagaan dan pemanfaatan/pengelolaan

$\mathrm{B}=$ Masih dalam proses penjagaan dan pemanfaatan/pengelolaan

$\mathrm{C}=$ Tidak dilakukan penjagaan dan pemanfaatan/pengelolaan

kondisi fisik (pasir) di wilayah Pesisir Desa Batununggul sudah dijaga dan di manfaatkan dengan baik oleh masyarakat Desa Batununggul dengan rata-rata $70,9 \%$. Dan yang masih dalam proses penjagaan dan Terumbu Karang

Pernyataan Responden (Kelompok Nelayan) Terhadap Kondisi Terumbu Karang Desa Batununggul

\begin{tabular}{|c|c|c|c|c|c|c|c|c|c|}
\hline \multirow{3}{*}{$\begin{array}{l}\mathbf{N} \\
\mathbf{O}\end{array}$} & \multirow{3}{*}{$\begin{array}{c}\text { Nama } \\
\text { Kelompok }\end{array}$} & \multicolumn{6}{|c|}{ Kondisi Terumbu Karang } & \multirow{3}{*}{$\begin{array}{c}\text { Total } \\
\mathbf{N}\end{array}$} & \multirow{3}{*}{$\%$} \\
\hline & & \multicolumn{2}{|c|}{$\begin{array}{c}\text { Sangat } \\
\text { Baik }\end{array}$} & \multicolumn{2}{|c|}{ Baik } & \multicolumn{2}{|c|}{$\begin{array}{c}\text { Kurang } \\
\text { Baik }\end{array}$} & & \\
\hline & & $\mathbf{N}$ & $\%$ & $\mathbf{N}$ & $\%$ & $\mathbf{N}$ & $\%$ & & \\
\hline 1 & $\begin{array}{l}\text { Punyan } \\
\text { Togol } \\
\text { Segara }\end{array}$ & 11 & $\begin{array}{c}78, \\
6\end{array}$ & 3 & $\begin{array}{c}21 \\
4\end{array}$ & 0 & 0 & 14 & 100 \\
\hline 2 & $\begin{array}{l}\text { Nusa } \\
\text { Bahari }\end{array}$ & 6 & 50 & 6 & 50 & 0 & 0 & 12 & 100 \\
\hline 3 & $\begin{array}{l}\text { Astitining } \\
\text { Samudra }\end{array}$ & 6 & 54 & 5 & $\begin{array}{c}45, \\
4\end{array}$ & 0 & 0 & 11 & 100 \\
\hline 4 & Sri Bhakti & 10 & $\begin{array}{c}55, \\
6\end{array}$ & 8 & $\begin{array}{c}44, \\
5\end{array}$ & 0 & 0 & 18 & \\
\hline \multicolumn{2}{|c|}{ Rata - rata } & - & $\begin{array}{c}59, \\
6\end{array}$ & - & $\begin{array}{c}40, \\
2\end{array}$ & - & 0 & - & - \\
\hline
\end{tabular}

Sumber: Analisis data primer 2017 kondisi Terubu Karangg Di Wilayah Pesisir Desa Batununggul tergolong sangat baik. Terdapat $59,6 \%$ para responden yang menyatakan kondisi terumbu karang di wilayah pesisir Desa Batunggul sangat baik. Sehingga para nelayan dapat pemanfaatan/pengelolaan kondisi pasir dengan rata-rata $27,1 \%$.

Indikator biologis meliputi aspek kondisi terumbu karang, ikan dan rumput laut di wilayah Desa Batununnggul.

\section{(Kelompok Nolisi Terumbu}

Rumput Laut

Pernyataan Responden (Kelompok Nelayan) Terhadap Kondisi Rumput Laut Desa Batununggul 


\begin{tabular}{|c|c|c|c|c|c|c|c|c|c|}
\hline \multirow{3}{*}{$\begin{array}{l}N \\
O\end{array}$} & \multirow{3}{*}{$\begin{array}{c}\text { Nama } \\
\text { Kelompok }\end{array}$} & \multicolumn{6}{|c|}{ Kondisi Rumput Laut } & \multirow{3}{*}{$\begin{array}{c}\text { Total } \\
\mathbf{N}\end{array}$} & \multirow{3}{*}{$\%$} \\
\hline & & \multicolumn{2}{|c|}{$\begin{array}{c}\text { Sangat } \\
\text { Baik }\end{array}$} & \multicolumn{2}{|c|}{ Baik } & \multicolumn{2}{|c|}{$\begin{array}{c}\text { Kurang } \\
\text { Baik }\end{array}$} & & \\
\hline & & $\mathbf{N}$ & $\%$ & $\mathbf{N}$ & $\%$ & $\mathbf{N}$ & $\%$ & & \\
\hline 1 & $\begin{array}{l}\text { Punyan } \\
\text { Togol } \\
\text { Segara }\end{array}$ & 8 & $\begin{array}{c}57 \\
1\end{array}$ & 6 & $\begin{array}{c}42 \\
8\end{array}$ & 0 & 0 & 14 & 100 \\
\hline 2 & $\begin{array}{l}\text { Nusa } \\
\text { Bahari }\end{array}$ & 7 & $\begin{array}{c}58, \\
3\end{array}$ & 5 & $\begin{array}{c}41 \\
7\end{array}$ & 0 & 0 & 12 & 100 \\
\hline 3 & $\begin{array}{l}\text { Astitining } \\
\text { Samudra }\end{array}$ & 7 & $\begin{array}{c}63 \\
6\end{array}$ & 4 & $\begin{array}{c}36 \\
3\end{array}$ & 0 & 0 & 11 & 100 \\
\hline 4 & Sri Bhakti & 10 & $\begin{array}{c}55 \\
6\end{array}$ & 8 & $\begin{array}{c}44 \\
5\end{array}$ & 0 & 0 & 18 & \\
\hline \multicolumn{2}{|c|}{ Rata - rata } & - & $\begin{array}{c}87 \\
4\end{array}$ & - & $\begin{array}{c}41 \\
3\end{array}$ & - & 0 & - & - \\
\hline
\end{tabular}

Sumber: Analisis data primer 2017

terdapat $\quad 87, \% \quad$ yang menunjukan kondisi rumput laut di daerah pesisir Desa Batununggul tergolong sangat baik dan dapat di manfaatkan untuk perekonomian masyarakat sekitar selain menangkap Pengelolaan Sumber Daya Pesisir di wilayah Pesisir Desa Batununggul

Pengelolaan sumber daya pesisir wilayah Desa Batununggul meliputi indikator sumber daya

Pernyataan Responden (Kelompok Nelayan) Terhadap Pengelolaan Sumber Daya Pesisir Desa Batununggul.

\begin{tabular}{|c|c|c|c|c|c|c|c|c|c|}
\hline \multirow{3}{*}{$\begin{array}{l}N \\
0\end{array}$} & \multirow{3}{*}{$\begin{array}{c}\text { Nama } \\
\text { Kelompok }\end{array}$} & \multicolumn{6}{|c|}{ Wilayah pesisir } & \multirow{3}{*}{$\begin{array}{c}\text { Total } \\
\mathbf{N}\end{array}$} & \multirow{3}{*}{$\%$} \\
\hline & & \multicolumn{2}{|c|}{ Sudah } & \multicolumn{2}{|c|}{$\begin{array}{c}\text { Sedang } \\
\text { dilakukan }\end{array}$} & \multicolumn{2}{|c|}{ Belum } & & \\
\hline & & $\mathbf{N}$ & $\%$ & $\mathbf{N}$ & $\%$ & $\mathbf{N}$ & $\%$ & & \\
\hline 1 & $\begin{array}{l}\text { Punyan } \\
\text { Togol } \\
\text { Segara }\end{array}$ & 9 & 75 & 3 & $\begin{array}{c}17 \\
6\end{array}$ & 0 & 0 & 14 & 100 \\
\hline 2 & Nusa & 7 & 58, & 5 & 41 & 0 & 0 & 12 & 100 \\
\hline
\end{tabular}

ikan. Serta masyarakat di daerah pesisir bisa melangsugkan kehidupannya dari pertanian rumput laut yang sangat baik dan kondisi daerah pesisir yang mendukung. perikanan dan ekosistem di Desa Batunggul. 


\begin{tabular}{|c|l|c|c|c|c|c|c|c|c|}
\hline & Bahari & & 3 & & 7 & & & & \\
\hline 3 & Astitining & 6 & 54 & 5 & 45, & 0 & 0 & 11 & 100 \\
& Samudra & & & & & & & \\
\hline 4 & Sri Bhakti & 10 & $\begin{array}{c}55, \\
6\end{array}$ & 8 & $\begin{array}{c}44, \\
5\end{array}$ & 0 & 0 & 18 & \\
\hline \multicolumn{2}{|c|}{ Rata - rata } & - & $\begin{array}{c}60, \\
7\end{array}$ & - & $\begin{array}{c}37, \\
3\end{array}$ & - & 0 & - & - \\
\hline
\end{tabular}

Sumber: Analisis data primer 2017

rata - rata $60,7 \%$ wilayah pesisir Desa Batununggul termasuk dengan baik oleh masyarakat sudah di manfaatkan dan dijaga setempat.

Cara Pengelolaan Sumber Daya Hayati, Non Hayati, dan Buatan

Cara pengelolaan sumber daya hayati, non hayati dan buatan pada wilayah pesisir Desa Batununggul meliputi beberapa indikator yaitu hayati (perikanan dan rumput laut, non hayati (pasir) dan buatan (bangunaan).

a). Hayati (perikanan dan rumput laut)

Indikator hayati meliputi aspek penangkapan ikan dan cara pembudidayaan rumput laut di Desa Batununggul, yaitu dapat di lihat pada tabel 4.15 hasil dari analisis atau pernyataan tentang penangkapan ikan dan cara pembudidayaan rumput laut di Desa Batununggul.

Pernyataan Responden (Kelompok Nelayan) Terhadap Penangkapan Ikan dan Cara Pembudidayaan Rumput Laut Desa Batununggul

\begin{tabular}{|c|c|c|c|c|c|c|c|}
\hline \multirow{3}{*}{ NO } & \multirow{3}{*}{$\begin{array}{c}\text { Nama } \\
\text { Kelompok }\end{array}$} & \multicolumn{4}{|c|}{$\begin{array}{l}\text { Penangkapan ikan dan cara } \\
\text { pembudidayaan rumput laut }\end{array}$} & \multirow{3}{*}{$\begin{array}{c}\text { Total } \\
\mathbf{N}\end{array}$} & \multirow{3}{*}{$\%$} \\
\hline & & \multicolumn{2}{|c|}{ Tradisiona } & \multicolumn{2}{|c|}{ Modern } & & \\
\hline & & $\mathbf{N}$ & $\%$ & $\mathbf{N}$ & $\%$ & & \\
\hline 1 & $\begin{array}{l}\text { Punyan } \\
\text { Togol } \\
\text { Segara }\end{array}$ & 12 & $\begin{array}{c}85, \\
7\end{array}$ & 2 & 14,2 & 14 & 100 \\
\hline 2 & Nusa Bahari & 10 & $\begin{array}{c}83 \\
3\end{array}$ & 2 & 16,7 & 12 & 100 \\
\hline 3 & $\begin{array}{l}\text { Astitining } \\
\text { Samudra }\end{array}$ & 8 & $\begin{array}{r}72, \\
7\end{array}$ & 2 & 18,2 & 11 & 100 \\
\hline 4 & Sri Bhakti & 15 & $\begin{array}{c}83, \\
3\end{array}$ & 3 & 16,7 & 18 & 100 \\
\hline
\end{tabular}




\begin{tabular}{|c|c|c|c|c|c|c|}
\hline Rata - rata & - & 81, & - & 16,5 & - & - \\
\hline
\end{tabular}

Sumber: Analisis data primer 2017

Tabel 4.15. menunjukan bahwa cara penangkapan ikan dan pembudidayaan rumput laut di Desa Batununggul yaitu dengan rata-rata $81,2 \%$ masih dengan cara tradisional. b). Non Hayati

Indikator non hayati meliputi aspek pemnfaatan pasir di Desa Batununggul, yaitu dapat di lihat pada tabel 4.16 hasil dari analisis atau pernyataan tentang pemnfaatan pasir di Desa Batununggul.

Pernyataan Responden (Kelompok Nelayan) Terhadap Pemnfaatan Pasir Desa Batununggul.

\begin{tabular}{|c|c|c|c|c|c|c|c|}
\hline \multirow{4}{*}{ NO } & \multirow{4}{*}{$\begin{array}{c}\text { Nama } \\
\text { Kelompok }\end{array}$} & \multicolumn{4}{|c|}{ Pemnfaatan pasir } & \multirow{4}{*}{$\begin{array}{c}\text { Total } \\
\mathbf{N}\end{array}$} & \multirow{4}{*}{$\%$} \\
\hline & & \multirow{2}{*}{\multicolumn{2}{|c|}{ Sesuai }} & \multirow{2}{*}{\multicolumn{2}{|c|}{ Tidak Sesuai }} & & \\
\hline & & & & & & & \\
\hline & & $\mathbf{N}$ & $\%$ & $\mathbf{N}$ & $\%$ & & \\
\hline 1 & $\begin{array}{l}\text { Punyan } \\
\text { Togol } \\
\text { Segara }\end{array}$ & 10 & $\begin{array}{c}71 \\
4\end{array}$ & 4 & 28,6 & 14 & 100 \\
\hline 2 & Nusa Bahari & 7 & $\begin{array}{c}58, \\
3\end{array}$ & 5 & 41,7 & 12 & 100 \\
\hline 3 & $\begin{array}{l}\text { Astitining } \\
\text { Samudra }\end{array}$ & 8 & $\begin{array}{c}72, \\
7\end{array}$ & 2 & 18,2 & 11 & 100 \\
\hline 4 & Sri Bhakti & 15 & $\begin{array}{c}83, \\
3\end{array}$ & 3 & 16,7 & 18 & 100 \\
\hline & lata - rata & & $\begin{array}{c}71 \\
4\end{array}$ & - & 26,3 & - & \\
\hline
\end{tabular}

Sumber: Analisis data primer 2017

Berdasarkan tabel 4.16 terdapat $71,4 \%$ yang menjawab bahwapemanfaatan pasir di Desa Batunungul sudah sesuai aturan atau c). Buatan

Indikator buatan meliputi aspek tempat atau rumah kelompok nelayan di Desa Batununggul, yaitu dapat di

awig - awig yang terdapat di Desa sehingga penggunaan pasir terbatasi atau tidak berlebihan dan tidak meninmbulkan abrasi.

lihat pada tabel 4.17 hasil dari analisis atau pernyataan tentang pemnfaatan pasir di Desa Batununggul.

Pernyataan Responden (Kelompok Nelayan) Terhadap Rumah Kelompok Nelayan Desa Batununggul

\begin{tabular}{|c|c|c|c|c|c|c|c|}
\hline \multirow{4}{*}{ NO } & \multirow{4}{*}{$\begin{array}{c}\text { Nama } \\
\text { Kelompok }\end{array}$} & \multicolumn{4}{|c|}{ Pemnfaatan pasir } & \multirow{3}{*}{$\begin{array}{c}\text { Total } \\
\mathbf{N}\end{array}$} & \multirow{4}{*}{$\%$} \\
\hline & & & & & & & \\
\hline & & \multicolumn{2}{|c|}{ Sesuai } & \multicolumn{2}{|c|}{ Tidak Sesuai } & & \\
\hline & & $\mathbf{N}$ & $\%$ & $\mathbf{N}$ & $\%$ & & \\
\hline
\end{tabular}




\begin{tabular}{|c|l|c|c|c|c|c|c|}
\hline 1 & $\begin{array}{l}\text { Punyan } \\
\text { Togol } \\
\text { Segara }\end{array}$ & 12 & $\begin{array}{c}85, \\
7\end{array}$ & 2 & 14,2 & 14 & 100 \\
\hline 2 & Nusa Bahari & 10 & $\begin{array}{c}83, \\
3\end{array}$ & 2 & 16,7 & 12 & 100 \\
\hline 3 & $\begin{array}{l}\text { Astitining } \\
\text { Samudra }\end{array}$ & 8 & $\begin{array}{c}72, \\
7\end{array}$ & 2 & 18,2 & 11 & 100 \\
\hline 4 & Sri Bhakti & 16 & $\begin{array}{c}88, \\
9\end{array}$ & 2 & 11,1 & 18 & 100 \\
\hline \multicolumn{2}{|c|}{ Rata - rata } & - & $\begin{array}{c}81, \\
9\end{array}$ & - & 15,1 & - & - \\
\hline
\end{tabular}

Sumber: Analisis data primer 2017

Berdasarkan tabel 4.17

terdapat $81,9 \%$ yang menjawab bahwa pembangun yang dibuat untuk membangun tempat atau rumah kelompok nelayan sudah sesuai aturan yang ada di Desa Batununggul dan tidak merusak lingkuungan setempat.

\section{Pembahasan}

\section{Karakteristik Sumber Daya Pada} Wilayah Pesisir Desa Batununggul

fisik yang meliputi aspek kondisi pasir wilayah di Desa Batununggul dalam aspek ini dilihat dari Tabel 4.12 (hal 52) bahwa pernyataan dari respoden (kelompok nelayan) sudah menjaga dan memanfaatkan/mengelola dengan baik oleh masyarakat Desa Batununggul dengan rata-rata 70,9\%. Adapun kelompok nelayan yang sudah menjaga atau memanfaatkan kondisi pasir di Desa Batununggul yang mendominasi adalah kelompok nelayan Sri Bhakti yaitu 83,3\% dan yang paling rendah kelompok nelayan Astitining Samudra sebesar 54,5\%. Sedangkan kelompok nelayan yang sedang melakukan proses penjagaan dan memanfaatkan/pengelolaan dengan rata-rata $27,1 \%$.

Cara Pengelolaan Sumber Daya Hayati, Non Hayati, dan Buatan pengelolaan sumber daya hayati, non hayati, dan buatan meliputi beberapa indikator yaitu hayati (perikanan dan rumput laut, non hayati (pasir) dan buatan (bangunan). Dalam hal ini pada indikator hayati (perikanan dan rumput laut) memperlihatkan bahwa kelompok nelayan yang ada di Desa Batununggul lebih banyak menggunakan cara penangkapan ikan dan pemudidayaan rumput laut secara tradisional dengan rata-rata $81,2 \%$ sedangkan dengan cara modern hannya $16,5 \%$. Hal ini ditunjujkan pada tabel 4.15 (hal 55). Jadi kelompok nelayan di Desa batununggul masih menggunakan cara tradisonal untuk menangkap ikan dan memudidayakan rumput laut. Dikarenakan dengan cara tradisional kelompok nelayan lebih erat memupuk rasa kebersamaan dalam menangkap ikan maupun memudidayakan rumput laut.

\section{SIMPULN DAN SARAN Simpulan}

Karateristik sumber daya pesisir Desa Batununggul sudah menunjukan adanya indikator yang sangat penting yaitu meliputi fisik dan bilogis dari karakteristik sumber daya pesisir 
daerah Batununggul yang masih dijaga dan di manfaatkan dengan baik tanpa merusak lingkungan fisik maupun biologis dari sumber daya pesisir tersebut dan Cara Pengelolaan Sumber Daya Pesisir Desa Batununggul sudah di kelola dan dijaga dengan baik oleh masyarakat setempat, ini dapat kita lihat dari hasil penangkapan ikan dan hasil dari pembudidayaan rumput laut.

\section{Saran}

Pemanfaatan dan pengelolaan sumber daya pesisir yang sering digunakan atau dimanfaatkan oleh masyarakat khususnya para nelayan hendaknya menjaga dengan baik, yaitu para nelayan harus tetap mengikuti aturan terutama aturan menangkap ikan dengan cara tidak menggunakan BOM air, racun dan lain-lainnya sehingga tidak merusak terumbu karang dan rumput laut dan Untuk menjaga sumber daya pesisir wilayah Desa Batununggul masyarakat juda hendak terus membangun sesuai aturan, sehingga bangunan yang di buat tertata rapi dan tidak merusak lingkungan disekitarnya.

\section{DAFTAR PUSTAKA}

Allen, G.R. 2008. Conservation Hotspots of Biodiversity and Endemism for Indo-Pacific Coral Reef Fishes. Aquat. Conserv., 18:541-556.

Arikunto, S. (1992). Prosedur Penelitian.Jakarta: Bina Aksara.

Badan Pusat Statistik, 2014. BPS.go.id :diaksespada 14 Februari 2016.

Badan Pusat Statistik (BPS) 2016 Kecamatan Nusa Penida.
Beatley, T. 1994. Introduction to Coastal Zone Management. Island Press.

ISBN 9781559632805.

Convention on Biological Diversity, 1993.

Dahuri, Rokhmin. 2001. Pengelolaan Sumber Daya Wilayah Pesisir dan Lautan Secara Terpadu.

Dinas Perikanan dan Kelautan, 2015. Data Statistik Perikanan Kabupaten Klungkung 2015.

Direktorat Jenderal Perikanan Tangkap. 2007. Petunjuk Teknis Penangkapan Ikan Ramah Lingkungan. Departemen Kelautan dan Perikanan, Jakarta.

Hadi . S . Yunus . 2010 . Metodologi Penelitian Wilayah Kontemporer . Yogyakarta : Pustaka Pelajar.

Ida Bagus Mantra . 2003. Demografi Umum. Edisi ke-2. Yogyakarta: Pustaka Belajar.

$\begin{array}{ccc}\text { Kartasapoetra, } & \text { G, } & \text { R.G. } \\ \text { Kartasapoetra, } & \text { dan } & \text { A.G. }\end{array}$ Kartasapoetra. 1986. Marketing Produk Pertanian dan Industri. Jakarta : PT Bina Aksara

Kay, R. And J. Alder. 1999. Coastal Planning and Management. E \& FN Spon. London. Nybaken,W.J. 1992. Biologi Laut, Suatu Pendekatan Ekologi. Gramedia, Jakarta.

McKenzie, L.J. and R.L. Yoshida. 2009. Seagrass Watch: Proceedings of a Workshop for Monitoring Seagrass Habitats in Indonesia. The Nature 
Conservancy, Coral Triange Center, Sanur, Bali, 9th May 2009.

Menteri Pemukiman dan Prasarana Wilayah. 2001. Tinjauan Aspek Penataan Ruang Dalam Pengelolaan Wilayah Laut dan Pesisir.

Mochamad Indrawan, 2007. Ekosistem.

Monografi Kecamatan Nusa PenidaTahun 2015.

Muhyadi. 1990. Organisasi, Teori, Strukturdan Proses: FPIPS, IKIP YOGYAKARTA.

Nandi. 2008."Pariwisata dan

Pengembangan Sumber daya Manusia". Jurnal

"GEA" Jurusan Pendidikan Geografi, April 2008, Vol. 8, No.1.

Nikijuluw, V. dan R. Basuki. 1996. Konsep Pedoman Umum Nilai Tukar Nelayan.Pusat Riset Pengolahan Produk dan Sosial Ekonomi Kelautan dan Perikanan.DKP. Jakarta.

Nita . 2013. Tingkat Produktivitas Budidaya Rumput Laut Pada Perairan Panttai

Di Kecamatan Nusa Penida Kabupaten Klungkung. Jurnal Pendidikan geografi, Undiksha, Singaraja.

Nurmalasari, Y. 2001. Analisis Pengelolaan Wilayah Pesisr Berbasis Masyarakat. www. Stmikim.ac.id/userfiles/jurnal\%20 yessi.pdf.
Post, Jan C. and Lundin, Carl G. Editors. 1996. Guidelines for integrated coastal zone management. Washington, D.C: World Bank

Profil Desa / Kelurahan Batununggul, 2016.

Soegiarto, A., S. Birowo dan Sukarno. 1976. Atlas Oseanografi Perairan Indonesia dan Sekitarnya. Lembaga Oseanologi Nasional Lembaga IImu Pengetahuan Indonesia. Buku No. 3. 327 Halaman. 